\title{
Do the Dento-Thalamic Connections of Genetic Absence Epilepsy Rats from Strasbourg Differ from Those of Control Wistar Rats?
}

\author{
Hüsniye Hacıoğlu Bay, ${ }_{1}^{1}$ Mazhar Özkan, ${ }^{1}$ Filiz Onat, ${ }^{2}$ and Safiye Çavdar ${ }^{3}$
}

\begin{abstract}
The thalamo-cortical circuit is important in the genesis of absence epilepsy. This circuit can be influenced by connecting pathways from various parts of central nervous system. The aim of the present study is to define the dento-thalamic connections in Wistar animals and compare the results with genetic absence epilepsy rats from Strasbourg (GAERS) using the biotinylated dextran amine (BDA) tracer. We injected BDA into the dentate nucleus of 13 ( $n=6$ Wistar and $n=7$ GAERS) animals. The dento-thalamic connections in the Wistar animals were denser and were connected to a wider range of thalamic nuclei compared with GAERS. The dentate nucleus was bilaterally connected to the central (central medial $[\mathrm{CM}]$, paracentral $[\mathrm{PC}]$ ), ventral (ventral medial [VM], ventral lateral [VL], and ventral posterior lateral [VPL]), and posterior (Po) thalamic nuclei in Wistar animals. The majority of these connections were dense contralaterally and scarce ipsilaterally. Contralateral connections were present with the parafascicular (PF), ventral posterior medial, ventral anterior (VA), and central lateral (CL) thalamic nuclei in Wistar animals. Whereas in GAERS, bilateral connections were observed with the VL and CM. Contralateral connections were present with the PC, VM, VA, and PF thalamic nuclei in GAERS. The CL, VPL, and Po thalamic nucleus connections were not observed in GAERS. The present study showed weak/deficit dento-thalamic connections in GAERS compared with control Wistar animals. The scarce information flow from the dentate nucleus to thalamus in GAERS may have a deficient modulatory role on the thalamus and thus may affect modulation of the thalamo-cortical circuit.
\end{abstract}

Keywords: BDA; connections; dentate nucleus; GAERS; thalamic nuclei

\section{Introduction}

T

HE CEREBELLUM Is no longer considered as a brain area related solely to motor skills. Experimental and clinical studies showed involvement of the cerebellum in cognitive functions (Albert et al., 2017; Budisavljevic and Ramnani, 2012; Igelstrom et al., 2017; Ignashchenkova et al., 2009; Manto, 2015; Shakiba, 2014; Stoodley and Limperopoulos, 2016; Verly et al., 2014). The impairment of execution of motor, cognitive, and sensorimotor tasks and learning was reported as dysfunction of cerebello-striato-cortical loops (Caligiore et al., 2017; Desmond and Fiez, 1998; Tzvi et al., 2017; Schmahmann, 2010; Middleton and Strick, 1997). Involvement of the dentate nucleus in autism, psychogenic ataxia-like symptoms, and impaired resting-state loops were reported as dysfunctions of cerebello-thalamo-cortical loops (Danielson et al., 2011; Olivito et al., 2017; Salih et al., 2010).

The cerebellum is connected to wide regions of the central nervous system (Bostan et al., 2013; Courchesne and Allen, 1997). The density of input to the cerebellum is 40 times higher than its output (Kandel and Mack, 2014), which shows the importance of its integrative functions (Stoodley and Schmahmann, 2009). The majority of the inputs of the cerebellum are to the cerebellar cortex, the outputs are through the deep cerebellar nuclei (lateral, medial and anterior, and posterior $[\mathrm{Po}]$ interposed).

The dentate nucleus (lateral nucleus) of the cerebellum has well-organized output channels that project to the primary motor, premotor, oculomotor, and prefrontal cortical areas through the thalamus (Middleton and Strick, 1998). It has been reported that the dentate nucleus has specific

Departments of ${ }^{1}$ Anatomy and ${ }^{2}$ Pharmacology and Clinic Pharmacology, Marmara University School of Medicine, Istanbul, Turkey.

${ }^{3}$ Department of Anatomy, Koç University School of Medicine, Istanbul, Turkey. 
organization, the dorsal parts of the nucleus project to the motor regions of the cerebral cortex through the motor relays of the thalamus, ventral parts of the nucleus project to nonmotor areas, and the prefrontal cortex through the ventral lateral (VL) thalamic nuclei (Bernard et al., 2013; Dum and Strick, 2003; Joyal et al., 2001; Kim et al., 1994; Middleton and Strick, 2001). Projections from both dorsal and ventral parts of the dentate nucleus take part in various important circuits, which have a role in both motor and nonmotor functions (Balsters et al., 2013; Bond et al., 2017; Middleton and Strick, 2001; Olivito et al., 2017;; Ramnani, 2012; Salih et al., 2010).

The majority of the information flow from the deep cerebellar nuclei to the cerebral cortex is through the thalamus. The thalamus is the main relay station of information before it reaches the cortex. The thalamic relay processes information that comes from the cerebellum and conveys it to its cortical target (Sherman and Guillery, 2009). However, what is it that the thalamus does to messages that flow from the dentate nucleus before it is transmitted to the cortex has not been demonstrated yet.

The important role of thalamo-cortical circuits in the genesis of absence epilepsy is well documented in both humans (Bertram, 2013; Crunelli and Leresche, 2002; Danober et al., 1998; Fletcher et al., 1996; Moeller et al., 2008; Yang et al., 2012) and experimental animals (Kandratavicius et al., 2014; McCormick and Contreras, 2001; Meeren et al., 2002). Studies have shown that thalamo-cortical circuits can be influenced by various parts of the central nervous system, which diverted researchers to examine the role of different parts of brain regions that influence the thalamo-cortical circuit.

Absence epilepsy is a neurological disease characterized by the presence of bilaterally synchronous spike-wave discharges (SWDs) in the encephalogram accompanied by loss of consciousness. The genetic absence epilepsy rats from Strasbourg (GAERS) are an inbred Wistar animal strain and are regarded as a reliable model of genetic generalized epilepsy and most of the genetic, pharmacological, and behavioral characteristics are similar to those observed in humans (Çarçak et al., 2009; Danober et al., 1998; Vergnes et al., 1986).

Disrupting thalamo-cortical activity patterns has proven to be a promising approach to stop generalized SWDs. Recent clinical and experimental studies showed the involvement of the cerebellum in the mechanism of absence epilepsy (Blumenfeld, 2012). Kros et al. (2015) showed that the cerebellar nuclei are potent modulators of pathological oscillations in thalamo-cortical network activity during absence seizures. Furthermore, Kros et al. (2015) provided strong evidence that cortical seizures can be stopped by optogenetic stimulation of the dentate and interposed cerebellar nuclei. Absence epilepsy is a brain network disease, thus in the present study, we aim to evaluate dento-thalamic connections using the biotinylated dextran amine (BDA) tracer in GAERS and control Wistar animals and compare the difference between the two strains.

\section{Materials and Methods}

In the present study, a total of 37 animals weighing 250 $300 \mathrm{~g}$ were used for the BDA injections. Of the 37 injections,
13 ( $n=6$ Wistar and $n=7$ GAERS) with minimal contamination of adjacent structures or along the pipette tract were included in the study (Fig. 1A, B). All animals were fed with a standard laboratory rat chow and tap water ad libitum and housed in Plexiglass cages with a 12-h light/12-h dark cycle in a temperature-controlled room $\left(20^{\circ} \mathrm{C} \pm 3^{\circ} \mathrm{C}\right)$. All procedures and animal housing before and after surgeries were approved by the Animal Care and Use Committee of Marmara University.

All animals were deeply anesthetized with intraperitoneal injection of the ketamine/xylazine mixture and surgery started after no cornea and extremity reflexes were observed. The $10 \mathrm{kDa}$ BDA (Invitrogen D-1956, Dextran, Biotin, Lysine Flexible, BDA-10.000) of $0.4 \mu \mathrm{L}$ was injected using a stereotaxic instrument to the coordinates of the dentate nucleus (AP: $-10.8 \mathrm{~mm}, \mathrm{~L}: 3.6 \mathrm{~mm}, \mathrm{~V}: 6.5 \mathrm{~mm}$ ) of adult Wistar rats $(n=6)$ and GAERS $(n=7$; Fig. $1 \mathrm{~A}, \mathrm{~B})$. Injections were performed by using a Hamilton syringe (HAM-80008, 1701 SN $10 \mu \mathrm{L}$ Syr) and Neurostar motorized stereotaxic frame (Neurostar, Tübingen, Germany). All animals survived for 7-10 days after BDA injections and animals were transcardially perfused with saline $(0.9 \% \mathrm{NaCl}, \mathrm{pH} 7.45 ; 200 \mathrm{~mL})$, followed by $500 \mathrm{~mL}$ of phosphate-buffered fixative containing $2 \%$ paraformaldehyde (PFA) and $1.5 \%$ glutaraldehyde (GA) solution (in $0.1 \mathrm{M}$ phosphate-buffered saline [PBS], pH 7.45; PBS Amresco E404-200TABS, PFA MERCK 1.04005.1000, GA MERCK 8.20603.1000). The brains were removed and postfixed in the same fixative solution overnight. All brains were collected in $30 \%$ sucrose solution at $+4^{\circ} \mathrm{C}$. Coronal serial sections $(50 \mu \mathrm{m})$ were cut using a cryomicrotome (Leica CM 1950) and free-floating sections were collected in well plates.

\section{BDA histochemistry}

Histochemistry was applied to every fourth section to visualize the BDA in the tissue, and sections were run in the avidin-biotinylated HRP (ABC) procedure, followed by the metal-enhanced diaminobenzidine (DAB-Ni) reaction. The procedure started with $10 \mathrm{~min}$ of sodium borohydride (Sigma-Aldrich S38714-486) incubation; PBS 0.1 M washing, twice for $10 \mathrm{~min}$ each; $\mathrm{ABC}$ standard solution (Vector Laboratories PK6100; Vectastain Elite ABC Standard Kit) incubation for $3 \mathrm{~h}$ at room temperature; PBS $0.1 \mathrm{M}$ wash for $10 \mathrm{~min}$; Tris buffer (TB) $0.05 \mathrm{M}$ (pH: 8.0) washes, twice for 10 min each; DAB-Ni [DAB Sigma D5905, ammonium nickel(II) sulfate hexahydrate Sigma A1827] preincubation in a dark room for $15 \mathrm{~min} ; \mathrm{H}_{2} \mathrm{O}_{2}$ reaction for 3-15 min in a dark room; TB $0.05 \mathrm{M}$ (pH: 8.0) wash for $10 \mathrm{~min}$, followed by PBS $0.1 \mathrm{M}$ wash for $10 \mathrm{~min}$; and finally, the sections were mounted. The sections were examined at $40 \times$ magnification under a light microscope. Ipsilateral, contralateral, and bilateral labeling was documented on four sections for each nucleus and for each animal. The density of labeled axons was evaluated (labeled) as follows: * scarce for the fiber number below 10, ** moderate for between 10 and 20 , and $* * *$ dense for the cell number above 20 .

\section{Results}

A total of 13 animals were included in the study (Fig. 1A, B). Subsequent to BDA injections into the dentate nucleus, 


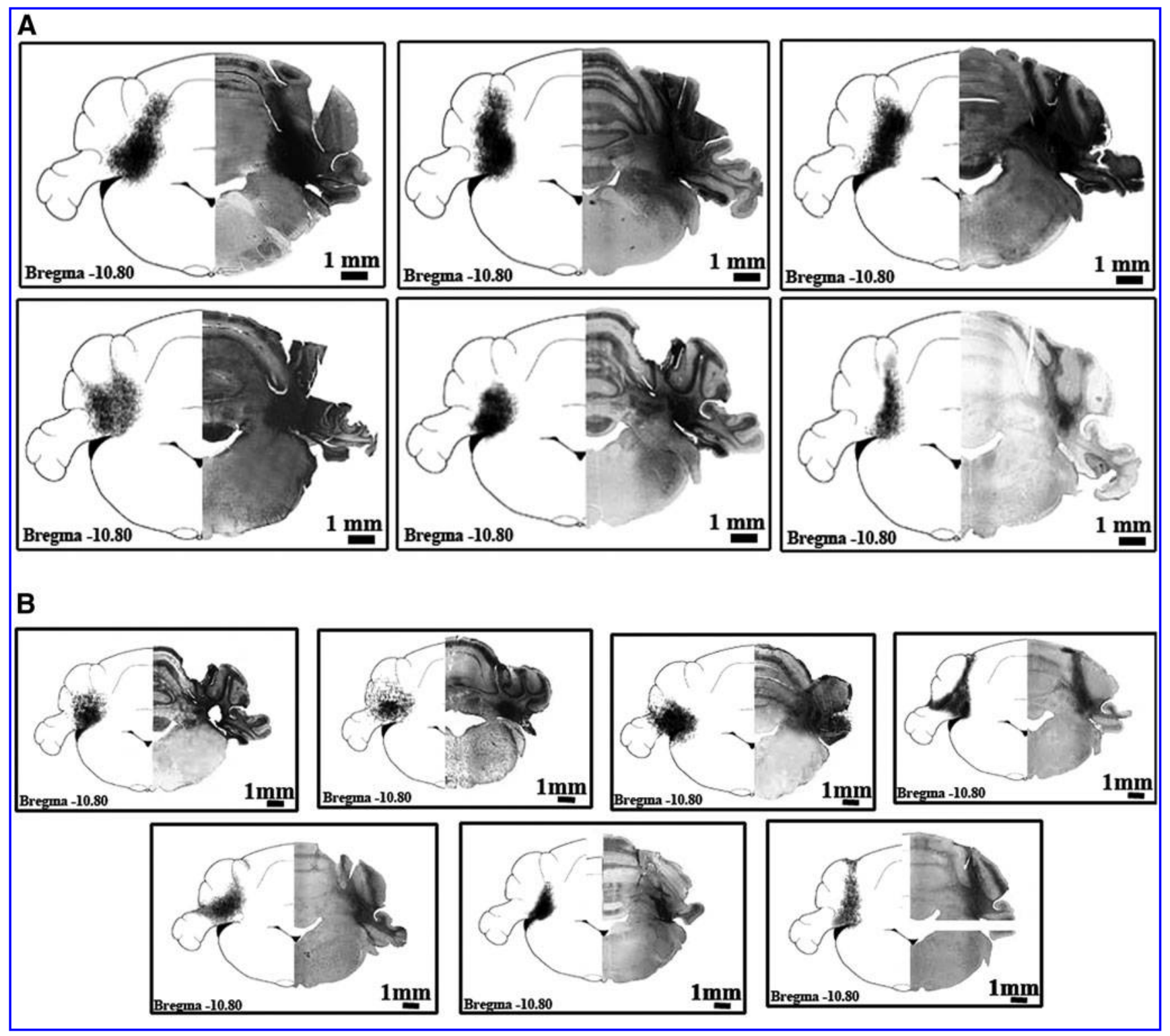

FIG. 1. (A) Photographs and schematic illustrations of the maximal BDA injection sites of six Wistar animals. (B) Photographs and schematic illustrations of the maximal BDA injection sites of 7 GAERS. BDA, biotinylated dextran amine.

only constantly labeled axons and cells in thalamic nuclei were documented (Table 1). The labeled axons and cells in thalamic nuclei, which were present in at least four animals for each strain, are included in the results, see Table 1 . The densities of bilateral, ipsilateral, and contralateral dentothalamic connections were documented for both GAERS and Wistar animals (Table 1).

\section{Dento-thalamic connections in Wistar animals}

The dentate nucleus was connected to a wide range of thalamic nuclei in Wistar animals, see Table 1. The major outputs of the cerebellum are from the dentate nucleus. The dentate nucleus consists of a hilum directed medially and the axons exit through the hilum (Fig. 2A, B). The dentate nucleus was bilaterally connected to central (central medial $[\mathrm{CM}]$ and paracentral $[\mathrm{PC}]$ ), ventral (ventral medial [VM], VL, and ventral posterior lateral [VPL]), and Po thalamic nuclei in Wistar animals (Fig. 3A-E). BDA labeling was denser in the contralateral compared with ipsilateral-related thalamic nuclei. Only contralateral connections were present with the central lateral (CL), ventral anterior (VA), ventral posterior medial (VPM), and parafascicular $(\mathrm{PF})$ thalamic nuclei in Wistar animals (Fig. 4A, B). Among dento-thalamic connections, the dentate nucleus was most strongly connected to the VL and Po thalamic nuclei (Table 1).

\section{Dento-thalamic connections in GAERS}

The dentate nucleus was connected to restricted thalamic nuclei in GAERS compared with Wistar animals, see Table 1 . The dentate nucleus was connected to only VL and CM thalamic nuclei, bilaterally and contralaterally to the PC, VM, VA, and PF thalamic nuclei (Fig. 4C). Among the 
Table 1. The Density of IPsilateral and Contralateral Dento-Thalamic Connections of GAERS and Wistar ANimals

\begin{tabular}{|c|c|c|c|c|}
\hline & \multicolumn{2}{|c|}{ Wistar } & \multicolumn{2}{|c|}{ GAERS } \\
\hline & Ipsilateral & Contralateral & Ipsilateral & Contralateral \\
\hline \multicolumn{5}{|l|}{ Central } \\
\hline CL & - & $*$ & - & - \\
\hline $\mathrm{CM}$ & $*$ & $*$ & $*$ & $*$ \\
\hline $\mathrm{PC}$ & $*$ & $*$ & - & $*$ \\
\hline \multicolumn{5}{|l|}{ Ventral } \\
\hline VM & $*$ & $*$ & - & $*$ \\
\hline VL & $*$ & $* * *$ & $*$ & $* *$ \\
\hline VA & - & $*$ & - & $*$ \\
\hline VPM & - & $*$ & - & $*$ \\
\hline VPL & $*$ & $*$ & - & - \\
\hline \multicolumn{5}{|l|}{ Posterior } \\
\hline Po & $*$ & $* *$ & - & - \\
\hline $\mathrm{PF}$ & - & $*$ & - & $*$ \\
\hline
\end{tabular}

* scarce for the fiber number below $10, * *$ moderate for between 10 and 20 , and $* * *$ dense for the cell number above 20.

CL, central lateral; CM, central medial; PC, paracentral thalamic nucleus; PF, parafascicular; Po, posterior; VA, ventral anterior; VL, ventral lateral; VPL, ventral posterior lateral; VM, ventral medial; VPM, ventral posterior medial.

dento-thalamic connections, the dentate nucleus was strongly connected to the contralateral VL thalamic nuclei in GAERS (Table 1). The majority of dento-thalamic connections in GAERS were contralateral (Table 1). The CL, VPL, and Po thalamic nucleus connections were not observed in GAERS. The dento-thalamic connections in GAERS were weaker compared with Wistar animals (Fig. 5A, B).

\section{Discussion}

The dento-thalamic connections were much denser and connected to a wider range of thalamic nuclei in Wistar animals compared with GAERS. The scarce information flow from the dentate nucleus to thalamus in GAERS may have a deficient modulatory role on the thalamus and thus may affect modulation of the thalamo-cortical circuit.

There are studies that report on connections of the dentate with specific thalamic nuclei in cats, monkeys, and humans using tract tracers and diffusion MRI (Bernard et al., 2013; Holsapple et al., 1991; Jimenez-Castellanos and ReinosoSuarez, 1985; Pelzer et al., 2017). However, collective data

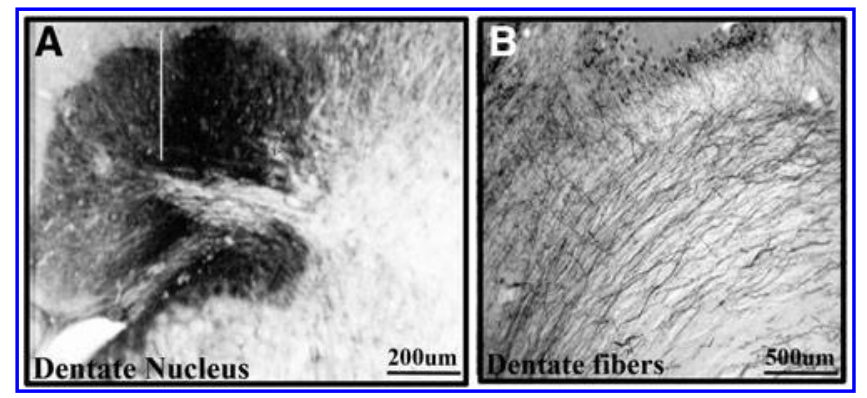

FIG. 2. (A) An example of high magnification of BDA injection site to the dentate nucleus. (B) Afferent and efferent fibers of the dentate nucleus.

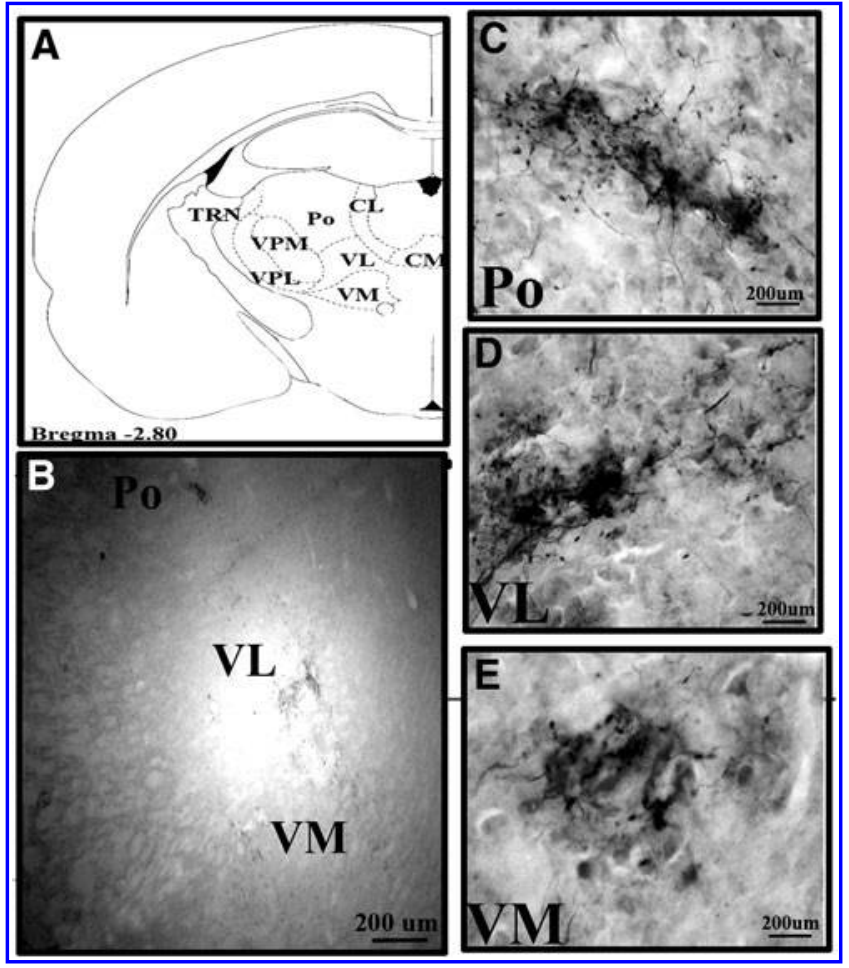

FIG. 3. (A) Schematic illustrations for localization of the BDA-labeled axons and cells in the thalamic nuclei for orientation. (B) Photograph showing localization of BDAlabeled axons and cells in the thalamic nuclei of Wistar animals in low magnification. (C) BDA-labeled axon terminals and fibers in the Po, (D) VL, and (E) VM thalamic nuclei of Wistar animals in high magnification. Po, posterior; VL, ventral lateral; VM, ventral medial.

regarding the dento-thalamic connections is rather sparse. The majority published connections highly correspond (VPM, VPL, VL, Po, IL, PF, and VM) with our results (Aumann et al., 1994; Bentivoglio and Kuypers, 1982; Bernard et al., 2013; Cavdar et al., 2018; Faull and Carman, 1978; Middleton and Strick, 1997). Gornati et al. (2018) reported that in vitro electrophysiological recordings revealed that optogenetic dentate nucleus stimulation resulted in enhanced charge transfer and action potential firing in VL neurons compared with VM or CL neurons. The present study has shown that VL connections were more dense compared with $\mathrm{VM}$ or CL, which may be the reason for the enhanced charge transfer and action potential firing in VL compared with VM and CL. Furthermore, singleaxon reconstructions of cerebellar-recipient zones within VL, VM, and CL reveal that their axons also spread throughout other regions, highlighting that the cerebellar input can affect a wide range of thalamo-cortical networks and functions (Deschênes et al., 1996).

White matter serves a critical role in organization of neural networks (Catani et al., 2012). Advances in brain imaging have revealed white matter impairment in most forms of neurodegeneration diseases, including Alzheimer's (Zhang et al., 2014), Huntington's (Gatto et al., 2015), and Parkinson's diseases (Duncan et al., 2016; Zhai et al., 2016), and psychological and behavioral disorders (Lener and Iosifescu, 2015; Seitz et al., 2016). There are studies that demonstrate white 

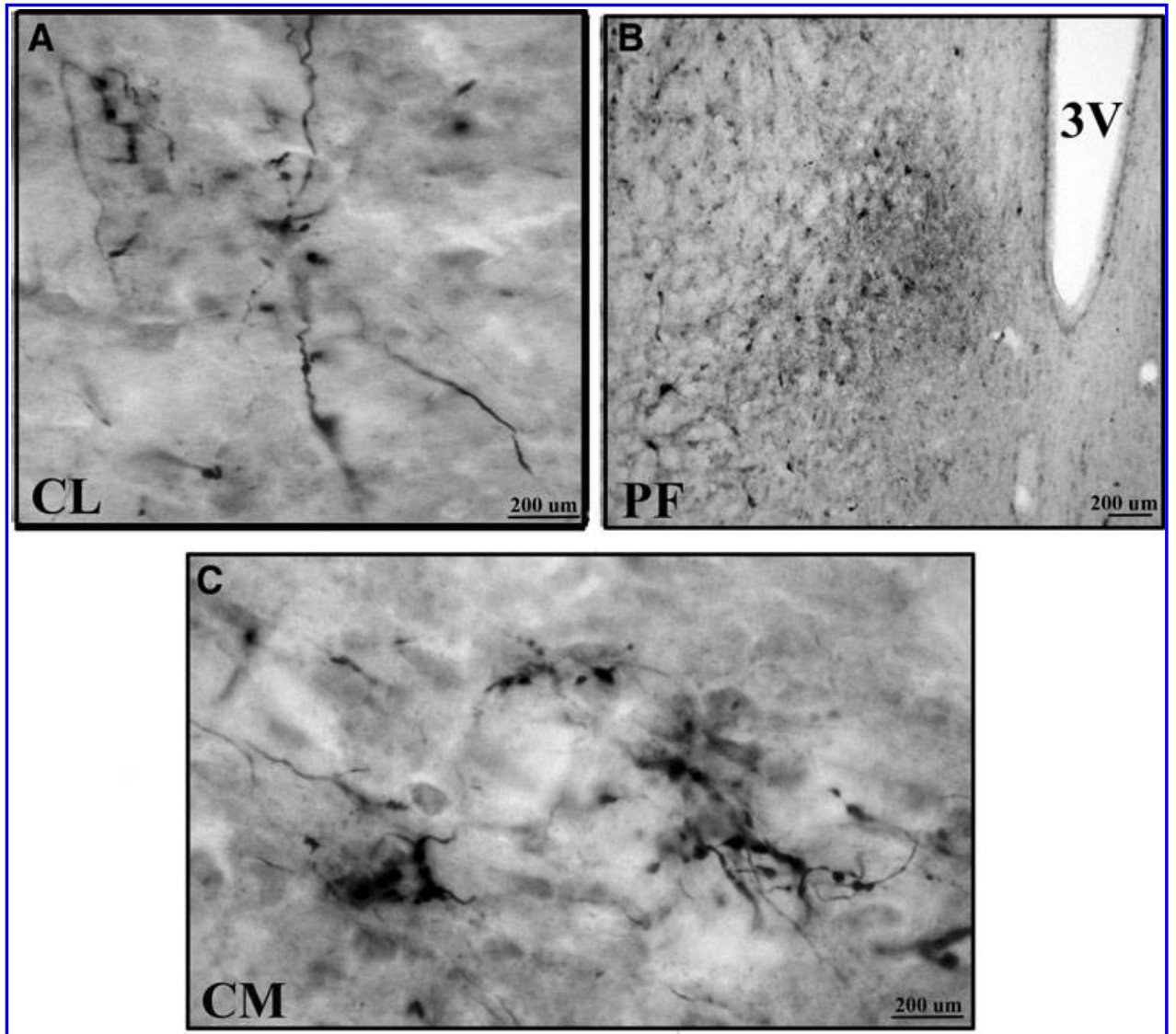

FIG. 4. (A) BDA-labeled axon terminals and fibers in the CL (B) and in the PF thalamic nuclei in Wistar animals. (C) BDA-labeled axon terminals and fibers in the $\mathrm{CM}$ thalamic nuclei in GAERS. CL, central lateral; $\mathrm{CM}$, central medial; PF, parafascicular. matter abnormalities in patients with temporal lobe epilepsy (Rodríguez-Cruces and Concha, 2015) and absence epilepsy (Correa et al., 2017). The present experimental study showed the absence of or weak dento-thalamic connections in GAERS, which may have a role in the pathophysiology of absence seizures.

Lesion studies suggested that thalamic nuclei, particularly the VL, VA, and VPL, have a permissive effect on partial and generalized seizures in animal models (Gasteiger et al., 1985; Mirski and Ferrendelli, 1984). The results of our study showed that VPL connections were not present in GAERS. Furthermore, Vergnes and Marescaux (1992) in- duced cortical and thalamic lesions and reported the effects on SWDs in genetic absence rat models. These results demonstrate that lesions of the lateral thalamus, including the specific relays (VPL, VPM, Po, VL, MDl, MDc, CL, and PC) and reticular nucleus, suppressed ipsilateral SWDs. The present study showed weak dento-thalamic connections with the former thalamic relay nuclei in GAERS compared with control Wistar animals, which may suggest an insufficient modulation of the thalamic relay nuclei through the dentate nucleus. Feline generalized penicillin animal epilepsy models have shown that thalamo-cortical circuits can be influenced by connecting pathways for generation of

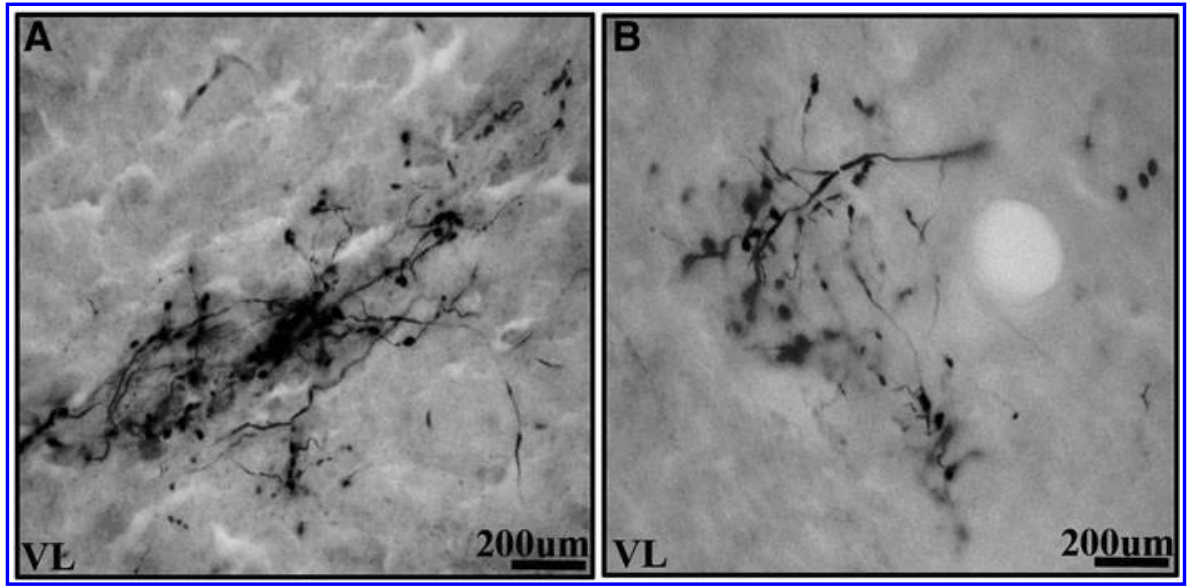

FIG. 5. Comparison of the density of labeled axons in the VL thalamic nuclei of the two experimental groups (A) Wistar animals versus (B) GAERS. 
typical SWD (Avoli and Kostopoulos, 1982; Norden and Blumenfeld, 2002). A recent study showed that cortical seizures can be manipulated by local injections of muscimol or gabazine to the interposed and dentate cerebellar nuclei, which strongly affected (increase and decrease, respectively) the occurrence of SWD at the cerebral cortex (Kros et al., 2015). Furthermore, Lüttjohann and van Luijtelaar (2012) studied interactions between the cortex and different thalamic nuclei in WAG/Rij rats for generation and maintenance of SWD using multisite cortical and thalamic local field potential recordings and reported that the earliest and strongest increases in coupling strength were seen between cortical layers $5 / 6$ and the Po thalamic nucleus and conclude that Po seems crucial for occurrence of SWDs. The dentate nucleus sends inhibitory projections to thalamic nuclei and mediates the information flow to the cortex. The results of the present study showed the absence of dento-Po thalamic connections in GAERS, which may play an important role in the occurrence of SWDs. Furthermore, the Po thalamic nucleus is a higher order nucleus that is thought to be involved in corticocortical communication (Sherman and Guillery, 2009) and can play a role in generalization of the SWD activity.

Direct thalamic and cerebellar electrostimulation has been examined as a potential therapeutic modality for human epilepsy (Shenoy et al., 2016). The CM nucleus of the thalamus is a stimulation target because of its diffuse projections to the cerebral cortex. The electroencephalogram (EEG) evidence in humans suggests that $\mathrm{CM}$ participates in propagation of absence and other generalized seizure activity (Velasco et al., 2000). The results of the present study showed that in both GAERS and Wistar animals, the dentate nucleus was bilaterally connected to the $\mathrm{CM}$ thalamic nucleus. Bilateral connection of the dentate nucleus with the CM thalamic nucleus may contribute in propagation of seizures to the cerebral cortex during epileptic seizures.

Although the mechanism is still not clear, the interaction between cerebellum and epilepsy is well known. The cerebellum is of interest in epilepsy because of the increased incidence of cerebellar atrophy in patients with partial and generalized epilepsy (Crooks and Mitchell, 2000; Gessaga and Urich, 1985). Both the increased likelihood of cerebellar atrophy in epileptic patients and the potential for cerebellar stimulation to decrease seizure frequency imply an important pathophysiologic role. Thus, the dentate nucleus for these reasons represents potential therapeutic targets that must be aggressively and thoroughly investigated.

Absence epilepsy is not a focal disorder, but rather a brain network disease. Thus, we propose that anatomical structures that have connections with specific thalamic nuclei may be involved in the epileptic mechanism and can affect the thalamo-cortical circuit. The dentate nucleus has strong connections with the thalamus and cerebral cortex, it seems quite plausible that it may have epileptogenic potential and must not be ignored. Thus, abnormal dentate input to the thalamus can affect a wide range of thalamocortical networks and functions. What role the cerebellum plays remains to be elucidated.

\section{Conclusion}

The results of this study show weak/deficit dento-thalamic connections in GAERS compared with Wistar animals.
These results may help to better understand the pathophysiology of absence epilepsy.

\section{Acknowledgment}

The authors would like to thank the Koç University Research Center for Translational Medicine (KUTTAM) for use of their facilities.

\section{Author Disclosure Statement}

No competing financial interests exist.

\section{Funding Information}

This research did not receive any specific grant from funding agencies in the public, commercial, or not-for-profit sectors.

\section{References}

Albert M, Barrantes-Freer A, Lohrberg M, Antel JP, Prineas JW, Palkovits M, et al. 2017. Synaptic pathology in the cerebellar dentate nucleus in chronic multiple sclerosis. Brain Pathol 27:737-747.

Aumann TD, Rawson JA, Finkelstein DI, Horne MK. 1994. Projections from the lateral and interposed cerebellar nuclei to the thalamus of the rat: a light and electron microscopic study using single and double anterograde labelling. J Comp Neurol 349:165-181.

Avoli M, Kostopoulos G. 1982. Participation of corticothalamic cells in penicillin-induced generalized spike and wave discharges. Brain Res 247:159-163.

Balsters JH, Whelan CD, Robertson IH, Ramnani N. 2013. Cerebellum and cognition: evidence for the encoding of higher order rules. Cereb Cortex 23:1433-1443.

Bentivoglio M, Kuypers HG. 1982. Divergent axon collaterals from rat cerebellar nuclei to diencephalon, mesencephalon, medulla oblongata and cervical cord. A fluorescent double retrograde labeling study. Exp Brain Res 46:339-356.

Bernard JA, Peltier SJ, Benson BL, Wiggins JL, Jaeggi SM, Buschkuehl M, et al. 2013. Dissociable functional networks of the human dentate nucleus. Cereb Cortex 24:2151-2159.

Bertram EH. 2013. Neuronal circuits in epilepsy: do they matter? Exp Neurol 3:67-74.

Blumenfeld H. 2012. Impaired consciousness in epilepsy. Lancet Neurol 11:814-826.

Bond KM, Brinjikji W, Eckel LJ, Kallmes DF, McDonald RJ, Carr CM. 2017. Dentate update: imaging features of entities that affect the dentate nucleus. Am J Neuroradiol 38:1467-1474.

Bostan AC, Dum RP, Strick PL. 2013. Cerebellar networks with the cerebral cortex and basal ganglia. Trends Cognitive Sci 17:241-254.

Budisavljevic S, Ramnani N. 2012. Cognitive deficits from a cerebellar tumour: a historical case report from Luria's Laboratory. Cortex 48:26-35.

Caligiore D, Mannella F, Arbib MA, Baldassarre G. 2017. Dysfunctions of the basal ganglia-cerebellar-thalamo-cortical system produce motor tics in Tourette syndrome. PLoS Comput Biol 13:1-34.

Çarçak N, Ferrandon A, Koning E, Aker RG, Özdemir O, Onat FY, et al. 2009. Effect of stage 2 kindling on local cerebral blood flow rates in rats with genetic absence epilepsy. Epilepsia 50:33-43.

Catani M, Dell'Acqua F, Vergani F, Malik F, Hodge H, Roy P, et al. 2012. Short frontal lobe connections of the human brain. Cortex 48:273-291. 
Cavdar S, Ozgur M, Kuvvet Y, Bay H, Aydogmus E. 2018. Cortical, subcortical and brain stem connections of the cerebellum via the superior and middle cerebellar peduncle in the rat. J Integr Neurosci 17:609-618.

Correa DG, Ventura N, Zimmermann N, Doring TM, Tukamoto G, Leme J, et al. 2017. Evaluation of deep gray matter volume, cortical thickness and white matter integrity in patients with typical absence epilepsy: a study using voxelwise-based techniques. Neuroradiol 59:237-245.

Courchesne E, Allen G. 1997. Prediction and preparation, fundamental functions of the cerebellum. Learn Mem 4:1-35.

Crooks R, Mitchell T, Thom M. 2000. Patterns of cerebellar atrophy in patients with chronic epilepsy: a quantitative neuropathological study. Epilepsy Res 41:63-73.

Crunelli V, Leresche N. 2002. Childhood absence epilepsy: genes, channels, neurons and networks. Nat Rev Neurosci 3:371-382.

Danielson NB, Guo JN, Blumenfeld H. 2011. The default mode network and altered consciousness in epilepsy. Behav Neurol 24:55-65.

Danober L, Deransart C, Depaulis A, Vergnes M, Marescaux C. 1998. Pathophysiological mechanisms of genetic absence epilepsy in the rat. Prog Neurobiol 55:27-57.

Deschênes M, Bourassa J, Doan VD, Parent A. 1996. A singlecell study of the axonal projections arising from the posterior intralaminar thalamic nuclei in the rat. Eur J Neurosci 8:329343.

Desmond JE, Fiez JA. 1998. Neuroimaging studies of the cerebellum: language, learning and memory. Trends Cogn Sci 2: 355-362.

Dum RP, Strick PL. 2003. An unfolded map of the cerebellar dentate nucleus and its projections to the cerebral cortex. J Neurophysiol 89:634-639.

Duncan GW, Firbank MJ, Yarnall AJ, Khoo TK, Brooks DJ, Barker RA, et al. 2016. Gray and white matter imaging: a biomarker for cognitive impairment in early Parkinson's disease? Mov Disord 1:103-110.

Faull RL, Carman JB. 1978. The cerebellofugal projections in the brachium conjunctivum of the rat I. The contralateral ascending pathway. J Comp Neurol 178:495-517.

Fletcher CF, Lutz CM, O'Sullivan TN, Shaughnessy JD, Jr., Hawkes R, Frankel WN, et al. 1996. Absence epilepsy in tottering mutant mice is associated with calcium channel defects. Cell 87:607-617.

Gasteiger EL, Albowitz B, Barken FM. 1985. Interictal afterdischarge in focal penicillin epilepsy: block by thalamic cooling. Exp Neurol 88:349-359.

Gatto RG, Chu Y, Ye AQ, Price SD, Tavassoli E, Buenaventura A, et al. 2015. Analysis of $\operatorname{YFP}(\mathrm{J} 16)-\mathrm{R} 6 / 2$ reporter mice and postmortem brains reveals early pathology and increased vulnerability of callosal axons in Huntington's disease. Hum Mol Genet 24:5285-5298.

Gessaga EC, Urich H. 1985. The cerebellum of epileptics. Clin Neuropathol 4:238-245.

Gornati SV, Schafer CB, Eelkman Rooda OHJ, Nigg AL, De Zeeuw CI, Hoebeek FE. 2018. Differentiating cerebellar impact on thalamic nuclei. Cell Rep 23:2690-2704.

Holsapple JW, Preston JB, Strick PL. 1991. The origin of thalamic inputs to the "Hand" representation in the primary motor cortex. J Neurosci 11:2644-2645.

Igelstrom KM, Webb TW, Graziano MSA. 2017. Functional connectivity between the temporoparietal cortex and cerebellum in autism spectrum disorder. Cereb Cortex 27:26172627.
Ignashchenkova A, Dash S, Dicke PW, Haarmeier T, Glickstein M, Thier P. 2009. Normal spatial attention but impaired saccades and visual motion perception after lesions of the monkey cerebellum. J Neurophysiol 102:3156-3168.

Jimenez-Castellanos J, Jr., Reinoso-Suarez F. 1985. Topographical organization of the afferent connections of the principal ventromedial thalamic nucleus in the cat. J Comp Neurol 236:297-314.

Joyal CC, Strazielle C, Lalonde R. 2001. Effects of dentate nucleus lesions on spatial and postural sensorimotor learning in rats. Behav Brain Res 122:131-137.

Kandel ER, Mack S. 2014. Principles of Neural Science. New York, NY: McGraw-Hill Medical.

Kandratavicius L, Balista PA, Lopes-Aguiar C, Ruggiero RN, Umeoka EH, Garcia-Cairasco N, et al. 2014. Animal models of epilepsy: use and limitations. Neuropsychiatr Dis Treat 10: 1693-1705.

Kim SG, Ugurbil K, Strick PL. 1994. Activation of a cerebellar output nucleus during cognitive processing. Science 265: 949-951.

Kros L, Eelkman Rooda OH, Spanke JK, Alva P, van Dongen MN, Karapatis A, et al. 2015. Cerebellar output controls generalized spike-and-wave discharge occurrence. Ann Neurol 77:1027-1049.

Lener MS, Iosifescu DV. 2015. In pursuit of neuroimaging biomarkers to guide treatment selection in major depressive disorder: a review of the literature. Ann N Y Acad Sci 1344:50-65.

Lüttjohann A, van Luijtelaar G. 2012. The dynamics of corticothalamo-cortical interactions at the transition from pre-ictal to ictal LFPs in absence epilepsy. Neurobiol Dis 47:49-60.

Manto M, Mariën P. 2015. Schmahmann's syndrome-identification of the third cornerstone of clinical ataxiology. Cerebellum Ataxias 2:2.

McCormick DA, Contreras D. 2001. On the cellular and network bases of epileptic seizures. Annu Rev Physiol 63:815-846.

Meeren HK, Pijn JP, Van Luijtelaar EL, Coenen AM, Lopes da Silva FH. 2002. Cortical focus drives widespread corticothalamic networks during spontaneous absence seizures in rats. J Neurosci 22:1480-1495.

Middleton FA, Strick PL. 1997. Dentate output channels: motor and cognitive components. Prog Brain Res 144:553-566.

Middleton FA, Strick PL. 1998. Cerebellar output: motor and cognitive channels. Trends Trends Cogn Sci 2:348-354.

Middleton FA, Strick PL. 2001. Cerebellar projections to the prefrontal cortex of the primate. J Neurosci 21:700-712.

Mirski MA, Ferrendelli JA. 1984. Interruption of the mammillothalamic tract prevents seizures in guinea pigs. Science 226: $72-74$.

Moeller F, Siebner HR, Wolff S, Muhle H, Boor R, Granert O, et al. 2008. Changes in activity of striato-thalamo-cortical network precede generalized spike wave discharges. Neuroimage 39:1839-1849.

Norden AD, Blumenfeld H. 2002. The role of subcortical structures in human epilepsy. Epilepsy Behav 3:219-231.

Olivito G, Clausi S, Laghi F, Tedesco AM, Baiocco R, Mastropasqua $\mathrm{C}$, et al. 2017. Resting-state functional connectivity changes between dentate nucleus and cortical social brain regions in autism spectrum disorders. Cerebellum 16:283-292.

Pelzer EA, Melzer C, Timmermann L, von Cramon DY, Tittgemeyer M. 2017. Basal ganglia and cerebellar interconnectivity within the human thalamus. Brain Struct Funct 222: 381-392.

Ramnani N. 2012. Frontal lobe and posterior parietal contributions to the cortico-cerebellar system. Cerebellum 11:366-383. 
Rodríguez-Cruces R, Concha L. 2015. White matter in temporal lobe epilepsy: clinico-pathological correlates of water diffusion abnormalities. Quant Imaging Med Surg 5:264-278.

Salih F, Breuer E, Harnack D, Hoffmann K-T, Ploner CJ. 2010. A syndrome of the dentate nucleus mimicking psychogenic ataxia. J Neurol Sci 290:183-185.

Schmahmann JD. 2010. The role of the cerebellum in cognition and emotion: personal reflections since 1982 on the dysmetria of thought hypothesis, and its historical evolution from theory to therapy. Neuropsychol Rev 20:236-260.

Seitz J, Zuo JX, Lyall AE, Makris N, Kikinis Z, Bouix S, et al. 2016.Tractography analysis of 5 white matter bundles and their clinical and cognitive correlates in early-course schizophrenia. Schizophr Bull 42:762-771.

Shakiba A. 2014. The role of the cerebellum in neurobiology of psychiatric disorders. Neurol Clin 32:1105-1115.

Shenoy C, Aodah Alzahrani H, Upton AR, Kamath MV. 2016. Electrostimulation for eefractory epilepsy: a review. J Long Term Eff Med Implants 26:253-260.

Sherman SM, Guillery RW. 2009. Exploring the Thalamus and its Role in Cortical Function. Cambridge: Mass; London: MIT Press.

Stoodley C, Schmahmann J. 2009. Functional topography in the human cerebellum: a meta-analysis of neuroimaging studies. Neuroimage 15:489-501.

Stoodley CJ, Limperopoulos C. 2016. Structure-function relationships in the developing cerebellum: evidence from early-life cerebellar injury and neurodevelopmental disorders. Semin Fetal Neonatal Med 21:356-364.

Tzvi E, Zimmermann C, Bey R, Münte TF, Nitschke M, Krämer UM. 2017. Cerebellar degeneration affects cortico-cortical connectivity in motor learning networks. Neuroimage Clin 16:66-78.

Velasco M, Velasco F, Velasco AL, Jimenez F, Brito F, Marquez I. 2000. Acute and chronic electrical stimulation of the centromedian thalamic nucleus: modulation of reticulocortical systems and predictor factors for generalized seizure control. Arch Med Res 31:304-315.

Vergnes M, Marescaux C. 1992. Cortical and thalamic lesions in rats with genetic absence epilepsy. J Neural Transm Suppl 35:71-83.

Vergnes M, Marescaux C, Depaulis A, Micheletti G, Warter J. 1986. Ontogeny of spontaneous petit mal-like seizures in Wistar rats. Brain Res 395:85-87.

Verly M, Verhoeven J, Zink I, Mantini D, Peeters R, Deprez S, et al. 2014. Altered functional connectivity of the language network in ASD: role of classical language areas and cerebellum. Neuroimage Clin 3:374-382.

Yang T, Guo Z, Luo C, Li Q, Yan B, Liu L, et al. 2012. White matter impairment in the basal ganglia-thalamocortical circuit of drug-naive childhood absence epilepsy. Epilepsy Res 99:267-273.

Zhai Y, Yamashita T, Nakano Y, Sun Z, Morihara R, Fukui Y, et al. 2016. Disruption of white matter integrity by chronic cerebral hypoperfusion in Alzheimer's disease mouse model. J Alzheimers Dis 52:1311-1319.

Zhang B, Xu Y, Zhu B, Kantarci K. 2014. The role of diffusion tensor imaging in detecting microstructural changes in prodromal Alzheimer's disease. CNS Neurosci Ther 20:3-9.

Address correspondence to: Safiye Çavdar

Department of Anatomy Koç University School of Medicine Sartyer Istanbul 34450 Turkey

E-mail: scavdar@ku.edu.tr 